\title{
Musculoskeletal Deformity
}

National Cancer Institute

\section{Source}

National Cancer Institute. Musculoskeletal Deformity. NCI Thesaurus. Code C78488.

Congenital or acquired deformity of the musculoskeletal system. 